\title{
Perceptions and Acceptability of a Smartphone App Intervention (ChildSafe) in Malaysia: Qualitative Exploratory Study
}

Teresa Sui Mien Yong ${ }^{1 *}$, BA; Komathi Perialathan ${ }^{1 *}$, BA, MSc; Masitah Ahmad ${ }^{1 *}$, BSc, MSc; Nurashma Juatan ${ }^{1^{*}}$, BA, MSc; Liana Abdul Majid ${ }^{2 *}$, MD; Mohammad Zabri Johari ${ }^{1^{*}}$, BSc, MSc, PhD

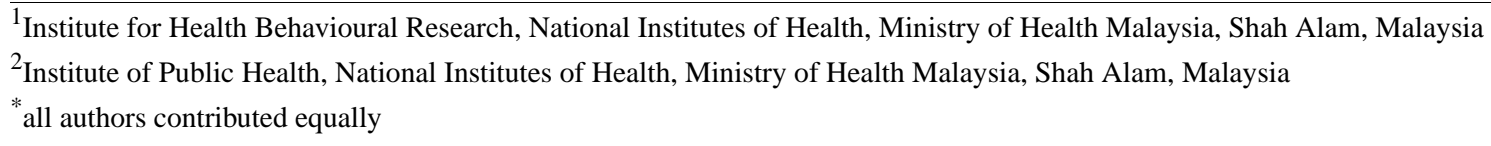

Corresponding Author:

Teresa Sui Mien Yong, BA

Institute for Health Behavioural Research

National Institutes of Health

Ministry of Health Malaysia

Block B3, No 1, Jalan Setia Murni U13/52

Section U13

Shah Alam, 40170

Malaysia

Phone: 60333627600 ext 8612

Fax: 60333627601

Email: teresa_yong@yahoo.co.uk

\begin{abstract}
Background: Home is a vulnerable place for accidental child injuries. Unintentional injuries are a leading cause of death, hospitalization, and disabilities. These injuries are considered preventable and if not tackled, they will continue to be a persisting problem. Smartphones have become increasingly important in our everyday life and is an important tool not only for communication but also for other purposes - they have apps that can be used for various purposes. Therefore, an app-based intervention (ChildSafe) was developed to assess and reduce child injury at home.

Objective: This study aimed to evaluate the acceptance of the ChildSafe smartphone app intervention by parents/guardians.

Methods: This study was conducted using a qualitative exploratory approach on selected participants of the ChildSafe intervention app study. A total of 27 semistructured in-depth interviews were carried out among parents or guardians who have at least one child between the age of 0 and 59 months in the area of Sungai Buloh, Selangor, between November 2017 and March 2018. Interview questions were developed from the consolidated framework for implementation research (CFIR). Interviews were recorded, transcribed verbatim, and data were thematically analyzed guided by CFIR.

Results: The study revealed users' perception on usability, feasibility, and acceptability toward the ChildSafe app. Three CFIR domains were identified: intervention characteristics, inner setting, and characteristics of individuals. A total of 5 constructs were revealed under intervention characteristics: evidence strength and quality, relative advantage, adaptability, trialability, and design quality and packaging; 2 under inner setting: implementation climate and readiness for implementation; and 4 under characteristics of individuals: knowledge and beliefs about the intervention, self-efficacy, individual stage of change, and other personal attributes. In general, participants felt the app is extremely useful and effective, easy to use, and purposeful in achieving home safety assessment via reminders. The app replaces the need for participants to search for information on home safety and dangers, as the app itself was designed as a tool to assess for this specific purpose. Even at the nascent stage and despite its limitations, the app has prompted users to consider and make changes around their own home. However, future versions of the app should be expanded to make it more attractive to users as it lacks interactive feedback and additional features.
\end{abstract}

Conclusions: Parents/guardians are accepting the use of the ChildSafe app to prevent child injury at home. However, further expansion and improvements are needed to increase the acceptability of this app by parents/guardians.

(JMIR Pediatr Parent 2021;4(2):e24156) doi: 10.2196/24156 


\section{KEYWORDS}

child safety; unintentional injuries; consolidated framework for implementation research (CFIR); characteristics of individuals; Mobile App Rating Scale (MARS)

\section{Introduction}

Home is where individuals or every family member feels secured and protected. Despite providing shelter and comfort, children can still be exposed to hazards and risks, and are vulnerable to unintentional injuries. Child injuries at home are one of the most common global public health threats to their survival [1]. Unintentional injuries refer to traffic injuries, drowning, poisonings, burns, and falls and are believed to be the leading cause of death, hospitalization, and disability globally and can cause long-lasting grief to the families, society, and nation [2].

After 15 years the Millennium Development Goals (MDGs) 4 still has not achieved the two-third reduction in under 5 mortality rate (U5MR) globally [3], with 5.82 million deaths reported among children under the age of 5 worldwide; injury-specific mortality rate in the under 5 age group was 73 per 100,000 population and 3654 years of life were lost per 100,000 population in 2015 [4]. The Malaysia National Health and Morbidity Survey revealed that the prevalence of home injury among children aged under 4 years was $2.5 \%$ in 1996 , whereas the rate among children aged under 7 years was $8.2 \%$ in 2011 [5].

Despite preventive measures, concerted efforts are still needed from various agencies to reduce further childhood injuries and the overall related mortality and morbidity issues [4]. The 2011 World Health Assembly urged member states to elevate child injury as a priority in the global public health policy [4]. The World Report on Child Injury Prevention highlighted the urgent need to address preventable cause of death and disability among vulnerable children worldwide; the World Health Organization, the United Nations Children's Fund, and other organizations have initiated joint effort initiatives to safeguard children's rights to healthy and safe environment free from injury and violence as emphasized by the United Nations Convention on the Rights of a Child (UNCRC) [2,6,7].

Henceforth, Sustainable Development Goals (SDGs) 2016-2030 have included targets for injury and violence prevention. The third goal is to reduce the deaths of children under 5 years of age from 9.8 million in 2000 to 5.4 million by 2017 [8].

Parenting interventions can reduce incidents of unintentional injuries in child in and around the home through the use of safety equipment and following existing safety recommendations by focusing on improving knowledge and perceptions on risks of injury, and importance of adopting safety practices [9]. Gaines and Schwebel [10] highlighted that parents and caregivers often have difficulties in identifying and recognizing hazards and perceived their own children to have less vulnerability to injuries. Importance of educating parents to find credible information and recommendations, and obtaining safety products best suited to their home were recommended.

Various intervention methods had been used with varying degrees of effectiveness, such as provision of educational materials, health care provider counselling, safety product distribution, and hands-on experiential learning provided at safety resource centers, to prevent injuries at home. However, it accentuated the need for wide-reaching, effective, and readily available methods of interventions to reach substantial parent and caregiver audiences [11].

Academics and clinicians are keenly interested in utilizing smartphones as an option for delivery of behavioral interventions [12]. Smartphone has become an integral part of our lives as it allows us to perform certain tasks and enables getting information, entertainment, and staying connected with others. The smartphone market is growing rapidly, with estimates suggesting that there are now 3.5 billion users worldwide (45.15\%), up from 2.5 billion (33.58\%) in 2016 [13]. The estimated number of smartphone users in Malaysia was 15.6 million $(75.9 \%)$ in $2017,78 \%$ in 2018 , and this number is expected to swell by $20.9 \%$ in 2023 [14,15]. Users have a strong attachment and dependency to their smartphones with at least one out of four users constantly checking their phones even without notification $(27.1 \%)$ [15].

Smartphones are predominantly seen as a promising and cost-effective medium to deliver health-related interventions [16]. To date, there are a few app-based interventions developed for unintentional home injuries; for example, Make Safe Happen for parents of children aged 0-12 years [11,17], Caregivers for children aged 0-6 years [18], Primary Caregivers of preschoolers aged 3-6 years [19,20], and Mothers with children under 3 years of age [21]. Education and promotion can be implemented through this platform to reach a larger segment of the population. With the rapid increase of smartphone usage in Malaysia and ease of access, a smartphone app intervention could be an effective solution for child injury prevention.

The novel idea of the ChildSafe app development came around as an experimental intervention designed to educate Malaysian parents and caregivers on child injury prevention at home. The ChildSafe app consists of 4 main features and functions: the home injury hazard assessment tool, interactive home safety tutorial, reminder feature addressing hazards identified during the assessment, and "tip of the week" feature. From the home injury hazard assessment tool, parents/guardians can identify and quantify existing hazards regarding childhood injury within the home as well as monitor changes occurring as a result of the interventions. The interactive home safety tutorial provides specific information on ways by which home injury hazard risks could be altered to make the environment safer for the child. The reminder feature serves as a feedback mechanism for parents/guardians to address the hazard and correct it. Tip of the week enhances the understanding of burden of childhood injury and knowledge on addressing it. At its nascent stage, acceptability of smartphone-based technology is important to be evaluated. Thus, a study was carried out to assess parents' perception and acceptability of the app in terms of functionality, acceptability, and ease of use. 
The consolidated framework for implementation research (CFIR), a conceptual framework that was established to guide systematic assessment of multilevel implementation to identify aspects that may affect implementation and effectiveness of an intervention, was used in this study. CFIR specifies 39 constructs acting as factors influencing intervention implementation and these are mapped into 5 major domains outlining potential barriers and facilitators of implementation or intervention outcomes: (1) characteristics of an intervention, (2) outer setting of the organization in which intervention is being implemented, (3) inner setting of the organization, (4) characteristics of individuals involved in the intervention, and (5) the implementation process [22]. With this framework in mind, this study aimed to evaluate acceptance of the ChildSafe smartphone app intervention by parents/guardians.

\section{Methods}

\section{Study Design}

This is a qualitative study assessing parental/guardian experience in using the ChildSafe smartphone app.

\section{Setting}

The study was performed in the Sungai Buloh area, Selangor, Malaysia. This suburban area was selected as it fulfilled the inclusion criteria of a growing community that is neither too rural nor overly urban based on ease of access and high penetration of smartphone use. Inclusion criteria for participants were as follows: households must have at least one child between 0 and 59 months of age, parent/guardian is available as participant, and owned an Android-based device.

\section{Intervention}

The ChildSafe app version 1.0 is a smartphone-based app designed to collect data and evaluate hazards risk reduction and prevention of child injuries at home, by focusing on feasible and measurable interventions within homes (Figure 1). The app was designed to map in-home risk of injuries among younger children (aged $<59$ months), and intended to stimulate hazard reduction (Figure 2). The app is installed on the participants' smartphone during the first visit. It has 4 main functions: a home injury hazard assessment tool, a home safety tutorial, a reminder feature for addressing hazards during the assessment, and tips on child safety. It is not publicly available, but for its use within this study a specific link to download the app was created.

Figure 1. App download screen.

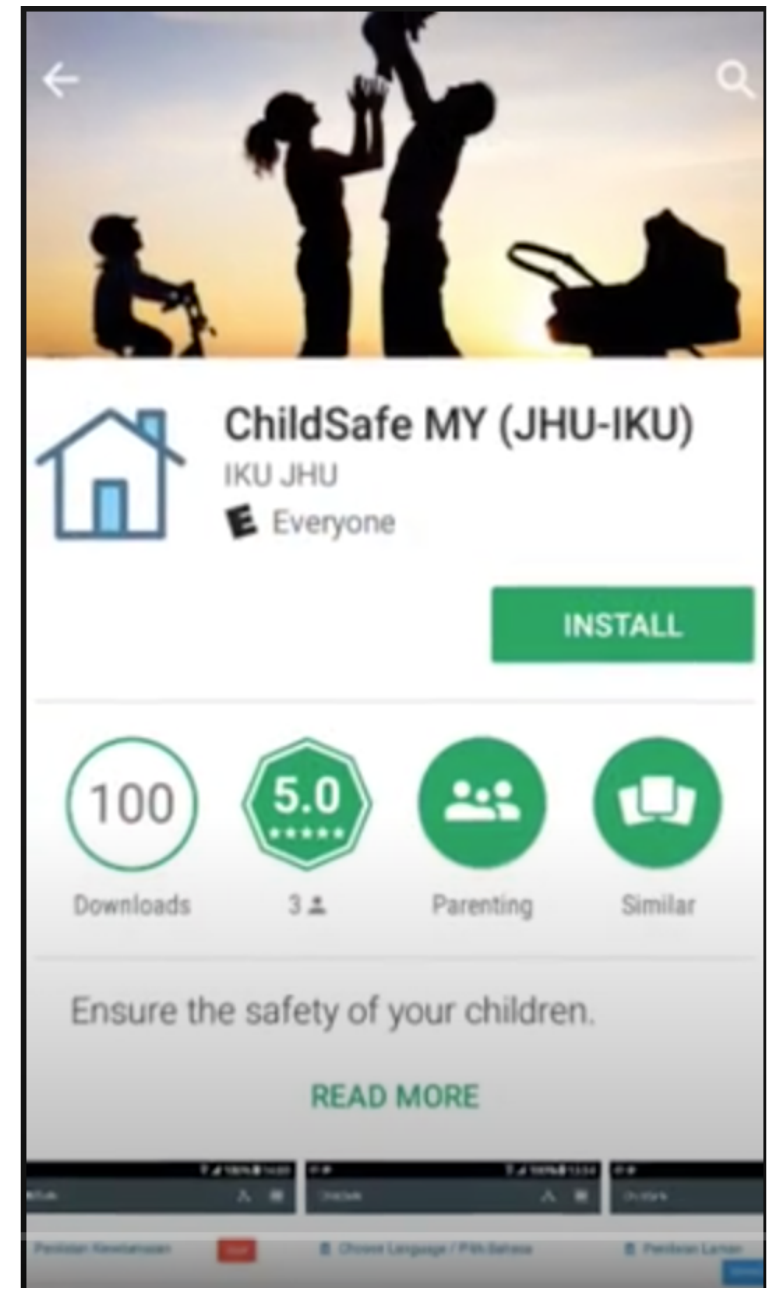


Figure 2. Safety assessment.

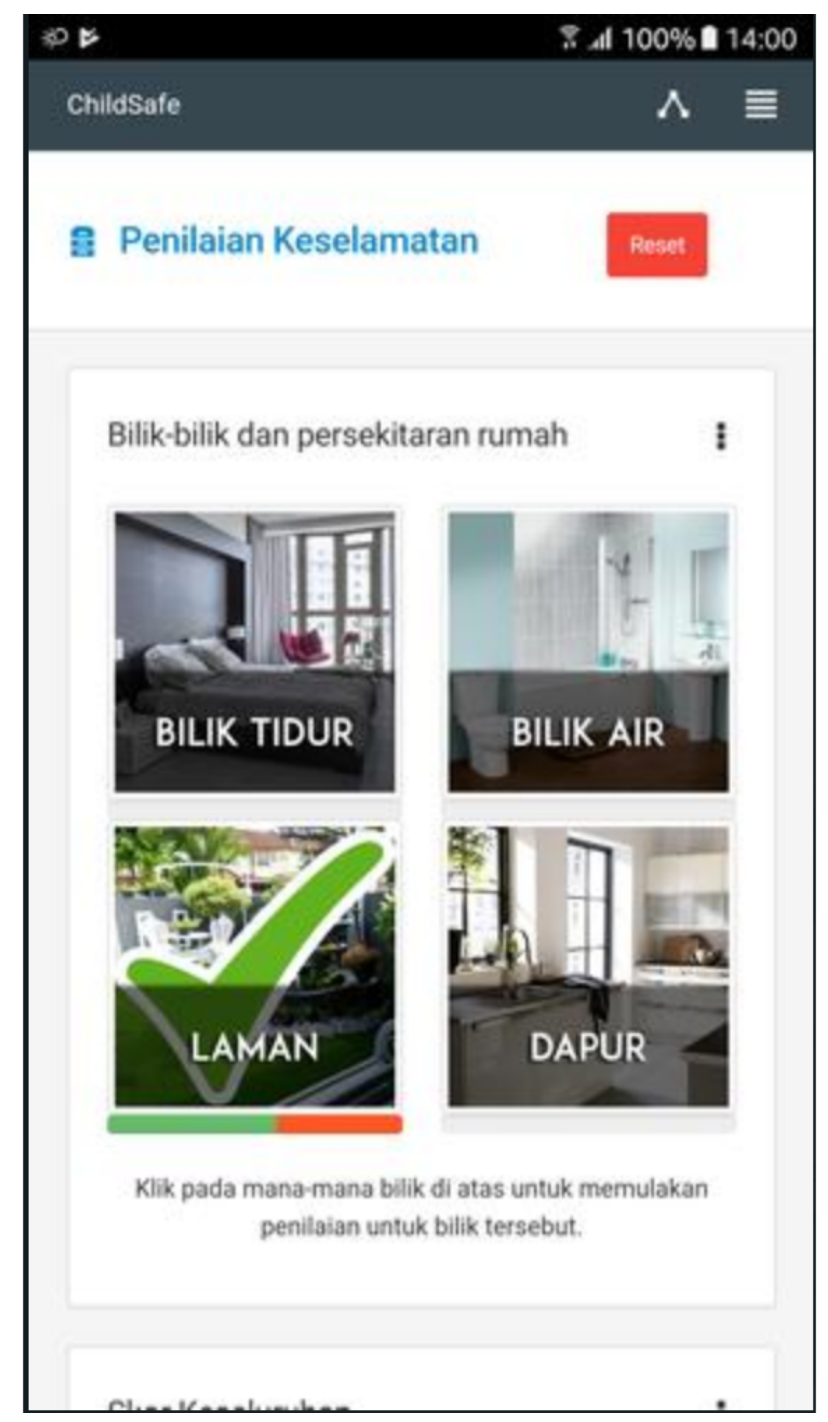

\section{Study Participants}

Study population included households with at least one child between the age of 0 and 59 months (Table 1). Participants were parents/guardians, able to read and converse in Malay or English, residing in the area of study during the study period, and fulfilled user app criteria of being either a complete user (completed tutorial and assessment), a partial user (completed at least tutorial but not assessment), or a nonuser (did not complete the tutorial or assessment). Participants were drawn from the main study (prospective cohort study) population and were identified by the main study research officers. A total of 27 parents/guardians participated. The number of participants was based on data saturation whereby the interview stopped at the 27 th participant when there was no more new information based on the questions asked. All participants approached agreed to be interviewed and gave consent. 
Table 1. Participants characteristics $(\mathrm{N}=158)$.

\begin{tabular}{|c|c|}
\hline Characteristic & Value, $\mathrm{n}(\%)$ \\
\hline \multicolumn{2}{|c|}{ Respondents' relationship to the child } \\
\hline Mother & $118(74.7)$ \\
\hline Father & $36(22.8)$ \\
\hline Others & $4(2.5)$ \\
\hline \multicolumn{2}{|l|}{ Gender of respondents } \\
\hline Male & $36(22.8)$ \\
\hline Female & $122(77.2)$ \\
\hline \multicolumn{2}{|l|}{ Age group (years) respondents } \\
\hline Under 30 & $29(18.4)$ \\
\hline $30-39$ & $96(60.8)$ \\
\hline 40 and over & $33(20.9)$ \\
\hline \multicolumn{2}{|l|}{ Educational level } \\
\hline Primary education and lower & $4(2.5)$ \\
\hline Secondary education & $45(28.5)$ \\
\hline Tertiary education & $109(69.0)$ \\
\hline \multicolumn{2}{|l|}{ House description } \\
\hline \multicolumn{2}{|l|}{ Type of accommodation } \\
\hline Flat & $22(13.9)$ \\
\hline Terrace single & $18(11.4)$ \\
\hline Terrace double & $118(74.7)$ \\
\hline \multicolumn{2}{|l|}{ House ownership } \\
\hline Own & $120(75.9)$ \\
\hline Rented & $38(24.1)$ \\
\hline
\end{tabular}

\section{Data Collection}

Interviews were conducted approximately 2 months into the main study implementation (between November 2017 and March 2018). This was done on the expectation that home safety assessments were completed and possible changes were made to improve child safety at home. Interview questions were developed from the CFIR framework which was used to the assess implementation process of a new intervention. The flow of questions was developed with specific prompting questions to assess user experience on the ChildSafe app. The questions were designed in both English and Malay to ease communication with participants.

Interviews were conducted face-to-face by research team members who were trained in qualitative methods and not acquainted to any participants to avoid potential response bias. Each in-depth interview was conducted at participants' home, lasted between 30 and 120 minutes, and was audio-recorded and transcribed verbatim. Confidentiality was ensured by removing participant identifiers from transcripts. Each transcript was cross-checked by the research team through audio listening and field notes.

\section{Data Analysis}

Data were analyzed using a thematic analysis, manually coded, and arranged using MS Excel by research team members who had previous experience in conducting qualitative analysis, were familiar with CFIR, and experts in their own field. The first level of analysis employed an inductive approach whereby researchers read transcribed interviews to identify preliminary themes independently. Relevant text segments were selected concerning acceptability and experience in using the app. At this stage, the researcher identified similar patterns in the data and developed first-level coding themes that could explain those patterns. Consensus on first-level themes was gained from other research members as well. The text segments were sorted using the identified themes. At the second level the research members independently identified and matched the themes together with best representative quotes for each theme and mapped them with existing domains and constructs under CFIR. Through consensus with other research members, the themes were placed under the construct that was deemed most suitable, and with identification of these constructs, the final level of identifying the respective domain that encompasses the constructs was completed (Table 2). The quotes that best represent the domains and constructs chosen to support the results are presented in Multimedia Appendix 1. 
Table 2. Perception of the ChildSafe Mobile App mapped on consolidated framework for implementation research domains.

\begin{tabular}{|c|c|c|}
\hline \multirow[t]{2}{*}{ Domain, constructs, and subconstructs } & \multicolumn{2}{|c|}{ Perception on change } \\
\hline & Positive presence & Negative presence \\
\hline \multicolumn{3}{|l|}{ Intervention characteristics } \\
\hline Evidence strength and quality & $\checkmark$ & \\
\hline Relative advantage & $\checkmark$ & \\
\hline Adaptability & $\checkmark$ & \\
\hline Trialability & $\checkmark$ & \\
\hline Design quality and packaging & $\checkmark$ & \\
\hline \multicolumn{3}{|l|}{ Inner setting } \\
\hline \multicolumn{3}{|l|}{ Implementation climate } \\
\hline Compatibility & $\checkmark$ & \\
\hline Relative priority & $\checkmark$ & \\
\hline Goals and feedback & $\checkmark$ & \\
\hline \multicolumn{3}{|l|}{ Readiness for implementation } \\
\hline Available resources & $\checkmark$ & $\checkmark$ \\
\hline Access to knowledge and information & $\checkmark$ & \\
\hline \multicolumn{3}{|l|}{ Characteristics of individuals } \\
\hline Knowledge and beliefs about the intervention & $\checkmark$ & $\checkmark$ \\
\hline Self-efficacy & $\checkmark$ & $\checkmark$ \\
\hline Individual stage of change & $\checkmark$ & $\checkmark$ \\
\hline Other personal attributes & $\checkmark$ & \\
\hline
\end{tabular}

\section{Availability of Data and Materials}

The data are not part of an online database but can be requested by writing to the Director of the Institute for Health Behavioral Research, National Institutes of Health, Ministry of Health Malaysia.

\section{Ethics Statement}

This study was granted ethical approval by the Medical Research Ethics Committee of the Ministry of Health Malaysia [KKM/NIHSEC/P19-1450(12)].

\section{Results}

\section{Overview}

A total of 27 transcripts were analyzed. From the 5 domains under CFIR, 3 were applicable: intervention characteristics, inner setting, and characteristics of individuals.

\section{Intervention Characteristics}

Of the 8 constructs in the intervention characteristics, 6 constructs which portrayed the app's acceptability were identified.

\section{Evidence Strength and Quality}

Users believed the ChildSafe app, which was created to help parents and caregivers with young children, will make their home safer as they become more aware and were able to identify the potential hazards in and around their house. Users feel the importance of smartphones as one of the channels of information that helps disseminate safety tips on child injury prevention. Hence, they have also recommended the app to their families and friends. Additionally, users strongly recommended that the app should be promoted in governmental institutions, schools, health clinics, and nursery centers.

\section{Relative Advantage (Observability)}

With regard to the ease of availability and use of smartphones, most users approached owned one to stay connected, and thus the app was easily accessed wherever/whenever they need to check and refer about safety tips at their own pace. Users also shared that it is time saving compared with surfing information in social media and existing conventional media, and that it makes the dissemination of health information on child injury prevention easier and have wider coverage.

Apart from that, learning is made easier with the app, it engages the users to make their home safe, and it fulfills their needs on hands-on experiential learning related to the child injury issue. The app is considered a cost-effective medium to deliver the home safety information and covers a wide range of multiple topics in a single platform. Users also highlighted that the app served as their reference guide and reminder (reminder list on behavioral hazard for safety tips of the week).

\section{Adaptability}

The developers of the mobile health (mHealth) app have customized it to address the local language needs of users for better comprehension. Users acknowledged that the bilingual 
option (ie, users can select either English or Malay based on their preference) made them easy to understand and follow instructions on the app.

\section{Trialability}

Because of the easy accessibility of the mobile app, most users approached were willing to download the app on child injury prevention to try it out in order to know more about its purpose and usefulness, which subsequently will contribute to making a decision on whether the app is favorable or unfavorable to adopt.

\section{Complexity}

Users perceived the app easy to operate conceptually and technically, as users who owned a smartphone would have accustomed to the functionality of the device and the app.

\section{Design Quality and Packaging}

Most users expressed their satisfaction and shared their appreciation on the feasibility and usability of the app aesthetics when navigating it (clear layout; color, size, and font used; image using real pictures; easy or clear instruction; and a wide coverage of all areas of the house concerning potential hazards at home for them to cross check at all times).

On top of that, the app does not take up too much memory space of the phone. Participants also noted that there is an interactive home safety tutorial section embedded and a constant safety reminder feature (to-do list on environmental hazard) will appear once they switch on the app whenever they have not addressed the particular hazard as recommended.

\section{Inner Setting}

\section{Implementation Climate}

\section{Compatibility}

Users perceived that because they have a smartphone and the installation process for the ChildSafe app is similar to that of other apps, it is fairly easy for them to understand and execute the task by taking safety precautions to prevent injuries to their children at home (social norms and values). Users expressed their enthusiasm to continue using the app as they found it rather convenient to learn about prevention of unintentional injuries. They strongly believed that the equipped knowledge and skills will help prevent unintentional injuries in their child as well as protect the child under their care.

\section{Relative Priority}

Users believed the app should be extended to have a wider coverage so that the community will become more aware of child safety at home and will benefit more. They also felt that this app is especially useful for parents, teachers, and caretakers.

\section{Goals and Feedback}

Users stated that the ChildSafe app will help them delve into child safety at home regardless of the level of knowledge they possess and increase their awareness on child safety at home. Users noted that the tips given via the app are very useful and that they can apply them to make improvements to their home to prevent unintentional injury. Based on the feedback from users, the objectives of the development of the mobile app have been achieved.

\section{Readiness for Implementation}

\section{Available Resources}

Because of the necessity and availability of smartphone in our daily lives, with most having at least one, the penetration of the ChildSafe app was higher, which made it easier to disseminate information on child injury at home. Users were eager to participate in the study as they want to ensure the safety of their children at home.

\section{Access to Knowledge and Information}

Most participants commented that the ChildSafe app was easy to use, understand, and do what is instructed to do. The instructions given allow users to think about what is important and useful, which may not have been thought of previously, especially for certain target populations. Users also felt that the educational information in the app is so comprehensive and more than what is offered in textbooks. The app indirectly engaged the users to spend some time checking each place in their home thoroughly before they can proceed to the next room.

\section{Characteristics of Individuals}

\section{Knowledge and Beliefs About the Intervention}

App information developed based on study and research is believed to be more reliable, trustable, and credible. In addition, the credibility of source is recommended by recruited staff members from the Ministry of Health. The app also acts as a preventive tool, as it presents a reminder of things to be put in place in every location of the house, thereby enabling users to be more aware of it. Because parents value the importance of their child's safety, this app helped them identify the common dangers at home, based on which improvements were made.

\section{Self-Efficacy}

The app indirectly increased the confidence and influenced the parents to be more cautious and take precautions necessary to avoid injury in children. Among the measures taken are taking time to check thoroughly every corners of the house they may have missed out to ensure they are safe and buying the right toys for their children to play with and avoiding buying small toys that their children might put into their mouth.

\section{Individual Stage of Change}

The ChildSafe app has prompted the users on the receptiveness to change by making home improvement changes to avoid unforeseen unintentional injury among their children at home. With reference to the verbatim analyzed, most of the users have made changes within a short period and successfully maintained the recommended behavior changes.

\section{Other Personal Attributes}

The app served as a learning tool for the users, as they were excited to venture more given the score they have achieved, as well as created awareness among the users. Whenever users completed a task, they will be awarded a score that indirectly created interest and motivated them to go to the next stage. Users own capability and completeness in accessing the 
smartphone enabled them to use the mobile-based ChildSafe app without much issue.

\section{Discussion}

\section{Principal Findings}

The CFIR conceptual framework has provided an analytic lens of evaluation to determine the key success of the ChildSafe app implementation. The intervention study results provide an overview of (1) the users' perceived characteristics of the innovation which will encourage them to use the ChildSafe app (behavioral intention), (2) the evaluation of the usability and feasibility of mHealth apps, (3) the innovation decision process that can facilitate the implementation of the app, and (4) the adoption phases that will lead to the adoption or resistance of the innovation.

Nilsen [23] has classified implementation frameworks into 5 categories: process models, determinant frameworks, classic theories, implementation theories, and evaluation frameworks. CFIR represents the determinant framework in this study to identify the confound factors that will contribute to the effectiveness of the interventions and their implementation [24], that is, evidence-based practice [25]. In line with the evidence-based practice, Damschroder et al [25] pointed out that in any intervention evaluation researchers must evaluate not only summative endpoint health outcomes but also the formative evaluation outlined in CFIR to assess the implementation effectiveness, the sustainability of the intervention, and dissemination of findings [25]. Dissemination and implementation studies particularly focus on the implementation impact to facilitate the adoption and implementation of the innovation or evidence-based intervention [26].

This ChildSafe app trial study is designed to evaluate the effectiveness of the parenting intervention in terms of the usability, feasibility, and acceptability (satisfaction on the innovation, eg, content or credibility) of parents and caregivers and their intention to reduce unintentional injuries among children at home [27].

Using CFIR and Diffusion of Innovation theory (proposed by Rogers) $[28,29]$ as a guidance to predict adoption of mHealth apps, we assessed the users' perceived characteristics of the innovation which will lead to the use of the ChildSafe app (behavior intention). Based on the findings of the study concerning the attributes of the innovation characteristics [30], our users have shown significant adoption of the mHealth app innovation. Users valued the app as a preventive and incremental (nonpreventive) innovation [31] (relative advantage) by making decisions to adopt, as it provides great advantages and benefits to manage their house from becoming an accident-prone site. In general, apps promoted by developers on a trial basis and those that are freely available will attract users willing to try them out (trialability). Furthermore, the reminder function of our app encouraged the users to check their surroundings on a frequent basis (trialability), as there will be a pop-up safety reminder on their smartphone screen when they turn on the app if they have not completed the checklist (self-monitoring). Most of the users perceived the app to be easy to understand and use (complexity). The availability of the app in bilingual language was well received by the users as they were able to choose either Malay or English for comprehension (adaptability). The compatibility of the app is relatively high for adoption as it is convenient to install because most users were already using smartphones and thus comfortable in downloading and installing apps. The portability of the smartphone makes it handy for the users to continue enjoying the mobile learning on the move [32] at a home setting (convenience of the mHealth intervention) [33] and navigate at any time (time saving).

Concerning the evaluation of mHealth app (design quality and packaging) quality criteria using the Mobile App Rating Scale (MARS) as proposed by Stoyanov et al [34,35], users relayed their satisfaction with the ChildSafe app. In terms of engagement, the app engaged the users by sending notification or reminder once they switch it on (interactivity) if they have not fully completed monitoring the things in each part of the house. Parents/caregivers (target group) also found the visual information for each part of the house together with the checklist and language used easy to understand. Users described that instructions via the app made them easy to understand and navigate (functionality) while the layout, suitability, and clear visuals (aesthetics) improved usability. Besides, the information presented is comprehensive and from a trustworthy source recommended by the Ministry of Health (information quality). Furthermore, the existing users' recommendation to others on the benefit of this app and the frequency of their usage of the app (subjective quality of the app) enhanced the perceived impact of the app on the user's knowledge, attitude, and intentions to address the targeted health behavior (ie, taking preventive measures to prevent unintentional injuries at home). Similarly, the app usability evaluation as addressed by Nielsen [36,37] depends on the 5 attributes: efficiency, satisfaction, learnability, memorability, and errors.

A full adoption and sustainment of the new innovation (ChildSafe app) is highly dependent on the 5 stages of the innovation decision process (ie, knowledge, persuasion, decision, implementation, and confirmation) [28], as suggested by Rogers. The first stage starts with knowledge (ie, access to information and knowledge and engaging), whereby the user is exposed to innovation, followed by persuasion, whereby the individual becomes interested and seeks further information about the innovation (affective). Self-efficacy (ie, one's self-perception about his/her capability in using the app and his/her confidence in making his/her home a safe environment), as envisioned in Bandura's social cognitive theory, plays a central role in successful behavior change. An individual's belief is influenced by previous experiences, social persuasion, perception, and affective response to the behavior [38]. Supporting this view in the theory of reasoned action which highlights intention, attitude, and subjective norms will determine the individual's intention to perform a behavior [39].

Interpersonal communication is used to spread word of the mouth concerning the testimonies on innovation usage (eg, network and communication/goals and feedback) and social reinforcement from peers (social system). This is within the adoption process that also contributes to the facilitation of the 
implementation effectiveness. The decision and implementation stages concerning the adoption of the innovation (readiness for implementation and executing) are determined by 2 predictors of attitude toward the usage, as indicated in the Technology Acceptance Model [40] on the perceived usefulness and perceived ease of use. Time of adoption also plays a crucial element in the adoption or resistance of the innovation [41]. Kaminski [42] pointed out that in Rogers' Diffusion of Innovation theory, the adoption phases are highly dependent on the 5 types of adopters, namely, innovators (technology enthusiast), early adopters (visionaries), early majority (pragmatist), late majority (conservative), and lastly the laggards (sceptic). Rogers' proposed phases are also comparable with the 5 stages of change in the Prochaska's Transtheoretical Model of Behavior Change [43], namely, the precontemplation (not thinking of changing), contemplation (aware and thinking about changing), preparation (take necessary steps to change), action (making changes within a short period), and maintenance (successfully maintain the behavior changes) [39]. The confirmation stage reflects on either the facilitation or hindrance of ChildSafe app usage (reflecting and evaluating).

These stages are also consistent with the scale criteria checklist (App Behavior Change Scale [ABACUS]) suggested by McKay [44] to assess the potential of an app in encouraging behavior change. ABACUS involves assessment of knowledge and information, goals and planning, feedback, and monitoring and actions [45]. Proctor et al [46] proposed 8 outcomes for evaluation: acceptability (user satisfaction with various aspects of the innovation, eg, content, complexity, and credibility), adoption (uptake, utilization, intention to try), appropriateness (compatibility, usefulness), feasibility (suitability for use), fidelity (adherence), implementation cost (cost-benefit), penetration (coverage access), and sustainability (maintenance) [45-47].

In particular, due to the rapid growth of technology, technology-assisted communication devices have been vastly utilized to deliver and enhance health interventions. Hence, there was some promising evidence from Omaki et al [48] that technology-assisted communication devices are indeed effective in improving knowledge, awareness, and creating favorable responsible actions pertaining to prevention of unintentional injuries. With regard to the study by Jabaley et al [49], using an iPhone (mobile device) as an in-home child safety intervention among 3 families with young children reduced home hazards to almost zero [46]. Similar studies on injury prevention apps for parents and caregivers have also been undertaken by Roberts et al [17], McKenzie et al [11], Chow et al [21], and Ning et al [18-20], and these indicated that such apps have improved parental safety knowledge, environmental modification, and successfully facilitated behavior change.

\section{Strengths and Limitations}

This study provides an underlying view on the importance of incorporating an evidence-based theoretical framework model and a health behavior change theory as a foundation when developing mHealth apps and designing mHealth interventions. CFIR itself is able to identify factors that determine the likelihood of implementing recommendations given by the app, its impact, and its effectiveness in behavior change to prevent or reduce unintentional home injuries in children, which in turn allows for future improvements to be made to the app to ensure all aspects of the framework are addressed for the benefit of the users.

The main limitation of the study pertain to the differences in cultural aspects. As the app was originally developed for Western use, some applicability does not resonate with the Malaysian population, which caused the users to feel disconnected when giving feedback. These included fire alarms, differences in toilet bowl designs, the absence of bathtubs in the Malaysian home, which in the Western countries are important elements in the assessment. Future studies may need to include a situational analysis or feasibility study before the start of the actual study.

\section{Recommendations}

The findings warrant future research studies to explore, examine, and provide insights into the potential areas for improvement on the developmental aspects with regard to the ChildSafe app:

- The study should be extended to the community and made available in different languages such as Mandarin and Tamil to reach out to different communities.

- Further improvement on the app coverage is necessary by incorporating missing features such as first aid; information on relevant emergency contact; setting reminders to check for functionality of safety devices; feedback; discussion forum to exchange opinions or ideas related to safety at home; teleconsultation or advice by experts or pediatricians for parents, caregivers, and teachers in elementary, primary, and secondary school; and interactive learning such as videos, interactive games, animation, and quiz not only for parents but also for children to learn; as well as providing regular updates to the information on the app, so that it can serve as an information hub and learning platform for all. In addition, improvisation of the tailored home safety information necessary to prevent injury in children and information on various safety aspects outside the house should be added to the app.

- Whether the app usability and feasibility in the particular community have improved the parents' knowledge, awareness, and self-empowerment to take responsibility for their child's health and safety should be investigated by examining the incidence rate of injury (epidemiological data) or by performing a comparison study between the intervention group and the control group during the duration of the study.

- A replicate study on the pretest of the app intervention in different community settings and population to assess the usability, acceptability, and feasibility is necessary.

\section{Conclusions}

Despite being a prototype and lacking advanced features, the ChildSafe app has been perceived as a very useful tool by the participants and has induced behavioral changes in users, such as taking actions to improve their living quarters to reduce unintentional injuries for their children at home. Although some issues highlighted warrant the need to improve future versions 
of the app, the study has indicated the possibilities and usefulness of app-based interventions for the Malaysian setting. The results of this study can be used as a guide to assist the relevant multidisciplinary policy makers to address the three
"Es" of interventions (education, enforcement, and engineering), as proposed in the Haddon matrix, to prevent unintentional injuries [2] on probably a larger scale should the improved app be made available publicly.

\section{Acknowledgments}

The authors thank the Director General of Health and Deputy Director General of Health (Research and Technical Support) Ministry of Health Malaysia for his permission to publish this article. Our utmost sincere thanks to Dr Manimaran Krishnan, the Director of the Institute for Health Behavioural Research, for his valuable comments and suggestions as a reviewer in improving the manuscript. We also thank the research team members of the study for their dedication and commitment: Norrafizah Jaafar, Mohamad Zaidan Zulkepli, Siti Nur Farhana binti Harun, Shahibul Bariah Mat Ghani, Noorul Aini Annuar, and Aiman Mukri. This study received funding from the National Institutes of Health (NIH) awarded to John Hopkins University as the main study recipient (intervention study) with the title "JHU-IKU Mobile Health for Child Injury Prevention in Malaysia (M-CHILD)" 1R21TW009930-01.

\section{Authors' Contributions}

TY is the main author who wrote the first draft, compiled all the written sections of this manuscript, and is the corresponding author for this manuscript. KP, MA, and NJ interpreted part of the data and cowrote sections of the manuscript. MJ is the senior author of this manuscript who is also responsible for the whole analysis, interpretation, refinement, and revision of the final draft of the manuscript.

\section{Conflicts of Interest}

None declared.

\section{Multimedia Appendix 1}

Example quotes organized thematically and mapped to CFIR domain and construct.

[DOCX File, 19 KB-Multimedia Appendix 1]

\section{References}

1. Sleet D. The Global Challenge of Child Injury Prevention. Int J Environ Res Public Health 2018 Sep 04;15(9):1921 [FREE Full text] [doi: 10.3390/ijerph15091921] [Medline: 30181462]

2. World Health Organization. World Report on Child Injury Prevention. Geneva, Switzerland: World Health Organization; 2008. URL: https://www.ncbi.nlm.nih.gov/books/NBK310641/ [accessed 2021-05-18]

3. Liu L, Oza S, Hogan D, Chu Y, Perin J, Zhu J, et al. Global, regional, and national causes of under-5 mortality in 2000-15: an updated systematic analysis with implications for the Sustainable Development Goals. Lancet 2016 Dec 17;388(10063):3027-3035 [FREE Full text] [doi: 10.1016/S0140-6736(16)31593-8] [Medline: 27839855]

4. Sharma SL, Reddy N, Ramanujam K, Jennifer MS, Gunasekaran A, Rose A, et al. Unintentional injuries among children aged 1-5 years: understanding the burden, risk factors and severity in urban slums of southern India. Inj Epidemiol 2018 Nov 05;5(1):41 [FREE Full text] [doi: 10.1186/s40621-018-0170-y] [Medline: 30393832]

5. Fact Sheet: Childhood Home Injuries in Malaysia. URL: http://www.fmsconference.net/speakerspdf2018/09/ Injury\%20Fact\%20Sheet-Home-Amar-v7.pdf [accessed 2021-05-20]

6. Sethi D, Towner E, Vincenten J, Segui-Gomez M, Racioppi F. European Report on Child Injury Prevention. Copenhagen, Denmark: World Health Organization; 2020.

7. Sethi D, Aldridge E, Rakovac I, Makhija A. Worsening Inequalities in Child Injury Deaths in the WHO European Region. Int J Environ Res Public Health 2017 Sep 26;14(10):e14101128 [FREE Full text] [doi: 10.3390/ijerph14101128] [Medline: 28954422]

8. United Nations Organization. The Sustainable Development Goals Report 2019. Geneva, Switzerland: World Health Organization; 2019.

9. Kendrick D, Mulvaney CA, Ye L, Stevens T, Mytton JA, Stewart-Brown S. Parenting interventions for the prevention of unintentional injuries in childhood. Cochrane Database Syst Rev 2013 Mar 28(3):CD006020. [doi: 10.1002/14651858.CD006020.pub3] [Medline: 23543542]

10. Gaines J, Schwebel DC. Recognition of home injury risks by novice parents of toddlers. Accid Anal Prev 2009 Sep;41(5):1070-1074. [doi: 10.1016/j.aap.2009.06.010] [Medline: 19664447]

11. McKenzie L, Roberts KJ, Clark R, McAdams R, Abdel-Rasoul M, Klein EG, et al. A randomized controlled trial to evaluate the Make Safe Happen ${ }^{\circledR}$ app-a mobile technology-based safety behavior change intervention for increasing parents' safety knowledge and actions. Inj Epidemiol 2018 Mar 12;5(1):5 [FREE Full text] [doi: 10.1186/s40621-018-0133-3] [Medline: $\underline{29527644]}$ 
12. Dennison L, Morrison L, Conway G, Yardley L. Opportunities and challenges for smartphone applications in supporting health behavior change: qualitative study. J Med Internet Res 2013 Apr;15(4):e86 [FREE Full text] [doi: 10.2196/jmir.2583] [Medline: 23598614]

13. Turner A. How Many Smartphones Are in the World?. 2020. URL: https://www.bankmycell.com/blog/ how-many-phones-are-in-the-world [accessed 2021-05-21]

14. Muller J. Smartphone Users in Malaysia 2015-2025. 2020. URL: https://www.statista.com/statistics/494587/ smartphone-users-in-malaysia/ [accessed 2021-05-21]

15. Suruhanjaya Komunikasi Dan Multimedia Malaysia, Malaysian Communications and Multimedia Commission. Hand Phone Users Survey 2018. Selangor Darul Ehsan: Malaysian Communications and Multimedia Commission; 2019. URL: https://www.mcmc.gov.my/skmmgovmy/media/General/pdf/HPUS2018.pdf [accessed 2021-05-21]

16. Abroms L, Padmanabhan N. Mobile phones for health communication to promote behavior change. In: Noar SM, Harrington NG, editors. eHealth Applications: Promising Strategies for Behavior Change. New York, NY: Routledge; 2012:147-166.

17. Roberts KJ, McAdams RJ, Kristel OV, Szymanski AM, McKenzie LB. Qualitative and Quantitative Evaluation of the Make Safe Happen App: Mobile Technology-Based Safety Behavior Change Intervention for Parents. JMIR Pediatr Parent 2019 Mar 14;2(1):e12022 [FREE Full text] [doi: 10.2196/12022] [Medline: 31518322]

18. Ning P, Gao D, Cheng P, Schwebel DC, Wei X, Tan L, et al. Needs Analysis for a Parenting App to Prevent Unintentional Injury in Newborn Babies and Toddlers: Focus Group and Survey Study Among Chinese Caregivers. JMIR Mhealth Uhealth 2019 Apr 30;7(4):e11957 [FREE Full text] [doi: 10.2196/11957] [Medline: 31038465]

19. Ning P, Chen B, Cheng P, Yang Y, Schwebel DC, Yu R, et al. Effectiveness of an app-based intervention for unintentional injury among caregivers of preschoolers: protocol for a cluster randomized controlled trial. BMC Public Health 2018 Jul 11;18(1):865 [FREE Full text] [doi: 10.1186/s12889-018-5790-1] [Medline: 29996813]

20. Ning P, Cheng P, Schwebel DC, Yang Y, Yu R, Deng J, et al. An App-Based Intervention for Caregivers to Prevent Unintentional Injury Among Preschoolers: Cluster Randomized Controlled Trial. JMIR Mhealth Uhealth 2019 Aug 09;7(8):e13519 [FREE Full text] [doi: 10.2196/13519] [Medline: $\underline{31400105]}$

21. Chow CB, Wong WH, Leung WC, Tang MH, Chan KL, Or CK, et al. Effectiveness of a Technology-Based Injury Prevention Program for Enhancing Mothers' Knowledge of Child Safety: Protocol for a Randomized Controlled Trial. JMIR Res Protoc 2016 Oct 31;5(4):e205 [FREE Full text] [doi: 10.2196/resprot.6216] [Medline: 27799138]

22. Keith RE, Crosson JC, O'Malley AS, Cromp D, Taylor EF. Using the Consolidated Framework for Implementation Research (CFIR) to produce actionable findings: a rapid-cycle evaluation approach to improving implementation. Implement Sci 2017 Feb 10;12(1):15 [FREE Full text] [doi: 10.1186/s13012-017-0550-7] [Medline: 28187747]

23. Nilsen P. Making sense of implementation theories, models and frameworks. Implement Sci 2015 Apr 21;10:53 [FREE Full text] [doi: 10.1186/s13012-015-0242-0] [Medline: 25895742]

24. Damschroder LJ. Clarity out of chaos: Use of theory in implementation research. Psychiatry Res 2020 Jan;283:112461 [FREE Full text] [doi: 10.1016/j.psychres.2019.06.036] [Medline: 31257020]

25. Damschroder LJ, Aron DC, Keith RE, Kirsh SR, Alexander JA, Lowery JC. Fostering implementation of health services research findings into practice: a consolidated framework for advancing implementation science. Implement Sci 2009;4(1):50 [FREE Full text] [doi: 10.1186/1748-5908-4-50] [Medline: 19664226]

26. Shelton RC, Lee M, Brotzman LE, Wolfenden L, Nathan N, Wainberg ML. What Is Dissemination and Implementation Science?: An Introduction and Opportunities to Advance Behavioral Medicine and Public Health Globally. Int J Behav Med 2020 Feb;27(1):3-20. [doi: 10.1007/s12529-020-09848-x] [Medline: 32060805]

27. Ellis LA, Augustsson H, Grødahl AI, Pomare C, Churruca K, Long JC, et al. Implementation of e-mental health for depression and anxiety: A critical scoping review. J Community Psychol 2020 Apr;48(3):904-920. [doi: 10.1002/jcop.22309] [Medline: 31944324]

28. Rogers EM. Diffusion of Innovation (5th Edition). New York, NY: Free Press; 2003.

29. Lin TTC, Bautista JR. Understanding the Relationships between mHealth Apps' Characteristics, Trialability, and mHealth Literacy. J Health Commun 2017 Apr;22(4):346-354. [doi: 10.1080/10810730.2017.1296508] [Medline: 28323546]

30. Sahin I. Detailed review of Rogers' diffusion of innovations theory and educational technology-related studies based on Rogers' theory. Turkish Online Journal of Educational Technology 2006;5:14-23 [FREE Full text]

31. Baghi R. Medical Treatment in the Digital Age: A Case Study of the Mobile Healthcare Applications in Shanghai. Copenhagen, Denmark: Copenhagen Business School; 2015.

32. Baran E, Uygun E, Altan T. Examining Preservice Teachers' Criteria for Evaluating Educational Mobile Apps. Journal of Educational Computing Research 2016 Jul 26;54(8):1117-1141. [doi: 10.1177/0735633116649376]

33. Christie HL, Bartels SL, Boots LMM, Tange HJ, Verhey FJJ, de Vugt ME. A systematic review on the implementation of eHealth interventions for informal caregivers of people with dementia. Internet Interv 2018 Sep;13:51-59 [FREE Full text] [doi: 10.1016/j.invent.2018.07.002] [Medline: 30206519]

34. Stoyanov SR, Hides L, Kavanagh DJ, Zelenko O, Tjondronegoro D, Mani M. Mobile app rating scale: a new tool for assessing the quality of health mobile apps. JMIR Mhealth Uhealth 2015 Mar 11;3(1):e27 [FREE Full text] [doi: 10.2196/mhealth.3422] [Medline: 25760773] 
35. Bardus M, van Beurden SB, Smith JR, Abraham C. A review and content analysis of engagement, functionality, aesthetics, information quality, and change techniques in the most popular commercial apps for weight management. Int J Behav Nutr Phys Act 2016 Mar 10;13:35 [ FREE Full text] [doi: 10.1186/s12966-016-0359-9] [Medline: 26964880]

36. Nielson J. Finding Usability problems through heuristic evaluation. In: Proceedings of the SIGHI Conference on Human Factors in Computing Systems. New York, NY: ACM; 1992:370-380.

37. Fung R, Chiu D, Ko E, Ho K, Lo P. Heuristic Usability Evaluation of University of Hong Kong Libraries' Mobile Website. The Journal of Academic Librarianship 2016 Sep;42(5):581-594. [doi: 10.1016/j.acalib.2016.06.004]

38. Middelweerd A, Te Velde SJ, Mollee JS, Klein MC, Brug J. App-Based Intervention Combining Evidence-Based Behavior Change Techniques With a Model-Based Reasoning System to Promote Physical Activity Among Young Adults (Active2Gether): Descriptive Study of the Development and Content. JMIR Res Protoc 2018 Dec 21;7(12):e185 [FREE Full text] [doi: 10.2196/resprot.7169] [Medline: $\underline{\text { 30578198] }}$

39. Gielen AC, Sleet D. Application of behavior-change theories and methods to injury prevention. Epidemiol Rev 2003;25:65-76. [doi: 10.1093/epirev/mxg004] [Medline: 12923991]

40. Tao D, Shao F, Wang H, Yan M, Qu X. Integrating usability and social cognitive theories with the technology acceptance model to understand young users' acceptance of a health information portal. Health Informatics J 2020 Jun;26(2):1347-1362 [FREE Full text] [doi: 10.1177/1460458219879337] [Medline: 31603378]

41. Dearing JW. Applying Diffusion of Innovation Theory to Intervention Development. Res Soc Work Pract 2009 Sep 01;19(5):503-518 [FREE Full text] [doi: 10.1177/1049731509335569] [Medline: 20976022]

42. Kaminski J. Diffusion of Innovation Theory. Canadian Journal of Nursing Informatics 2011 Jun 19;6(2):e1 [FREE Full $\underline{\text { text }]}$

43. Prochaska J, DiClemente C. Stages and processes of self-change of smoking: Toward an integrative model of change. Journal of Consulting and Clinical Psychology 1983;51(3):390-395. [doi: 10.1037/0022-006X.51.3.390]

44. McKay FH, Slykerman S, Dunn M. The App Behavior Change Scale: Creation of a Scale to Assess the Potential of Apps to Promote Behavior Change. JMIR Mhealth Uhealth 2019 Jan 25;7(1):e11130 [FREE Full text] [doi: 10.2196/11130] [Medline: 30681967]

45. McKay FH, Wright A, Shill J, Stephens H, Uccellini M. Using Health and Well-Being Apps for Behavior Change: A Systematic Search and Rating of Apps. JMIR Mhealth Uhealth 2019 Jul 04;7(7):e11926 [FREE Full text] [doi: 10.2196/11926] [Medline: 31274112]

46. Proctor E, Silmere H, Raghavan R, Hovmand P, Aarons G, Bunger A, et al. Outcomes for implementation research: conceptual distinctions, measurement challenges, and research agenda. Adm Policy Ment Health 2011 Mar;38(2):65-76 [FREE Full text] [doi: 10.1007/s10488-010-0319-7] [Medline: 20957426]

47. Hermes EDA, Lyon AR, Schueller SM, Glass JE. Measuring the Implementation of Behavioral Intervention Technologies: Recharacterization of Established Outcomes. J Med Internet Res 2019 Jan 25;21(1):e11752 [FREE Full text] [doi: 10.2196/11752] [Medline: 30681966]

48. Omaki E, Rizzutti N, Shields W, Zhu J, McDonald E, Stevens MW, et al. A systematic review of technology-based interventions for unintentional injury prevention education and behaviour change. Inj Prev 2017 Apr;23(2):138-146. [doi: 10.1136/injuryprev-2015-041740] [Medline: 26787740]

49. Jabaley J, Lutzker J, Whitaker D, Self-Brown S. Using iPhones ${ }^{\text {TM }}$ to Enhance and Reduce Face-to-face Home Safety Sessions within SafeCare ${ }^{\circledR}$ : An Evidence-based Child Maltreatment Prevention Program. J Fam Viol 2011 Apr 20;26(5):377-385. [doi: 10.1007/s10896-011-9372-6]

\section{Abbreviations}

ABACUS: App Behavior Change Scale

CFIR: consolidated framework for implementation research

MARS: Mobile App Rating Scale

MDGs: Millennium Development Goals

SDGs: Sustainable Development Goals

U5MR: under 5 mortality rate

UNCRC: United Nations Convention on the Rights of a Child 
Edited by S Badawy, MD, MS; submitted 06.09.20; peer-reviewed by I Zamberg, T Alessa, KL Mauco; comments to author 20.10.20; revised version received 14.12.20; accepted 11.03.21; published 01.06.21

Please cite as:

Yong TSM, Perialathan K, Ahmad M, Juatan N, Abdul Majid L, Johari MZ

Perceptions and Acceptability of a Smartphone App Intervention (ChildSafe) in Malaysia: Qualitative Exploratory Study

JMIR Pediatr Parent 2021;4(2):e24156

URL: https://pediatrics.jmir.org/2021/2/e24156

doi: $10.2196 / 24156$

PMID:

(C) Teresa Sui Mien Yong, Komathi Perialathan, Masitah Ahmad, Nurashma Juatan, Liana Abdul Majid, Mohammad Zabri Johari. Originally published in JMIR Pediatrics and Parenting (https://pediatrics.jmir.org), 01.06.2021. This is an open-access article distributed under the terms of the Creative Commons Attribution License (https://creativecommons.org/licenses/by/4.0/), which permits unrestricted use, distribution, and reproduction in any medium, provided the original work, first published in JMIR Pediatrics and Parenting, is properly cited. The complete bibliographic information, a link to the original publication on https://pediatrics.jmir.org, as well as this copyright and license information must be included. 